\title{
IS CONSERVATION OF CULTURAL PROPERTIES \\ A TOOL FOR TOURISM HOSPITALTY?
}

\author{
N. Gul ASATEKIN ${ }^{1}$
}

\begin{abstract}
The paper addresses to the perennial question "Is tourism a tool for the conservation of cultural properties?" or, vice versa: "Is conservation of cultural properties a tool for tourism?" Author, for being a conservation architect, asks the question according to the main theme of the conference as "Should architectural conservation activities mainly aim at fulfilling the requirements and expectations of the tourism for sake of touristic hospitality?"Thus, approach to the Congress theme "tourism hospitality" will be from the viewpoint of conservation theories, conservation practice and conservation politics. The paper aims to address the interrelation and/or contradiction between tourism and conservation of cultural and natural heritage. It will use an amalgam of theoretical approaches and basic international documents in relation to the management of tourism and cultural heritage. Interaction and/or contradiction between the tourist and the inhabitant will create the basis to question the term "hospitality". Arguments and discussions will be exemplified by cases from Turkey and some other European countries. The clues of basic principles pertaining to a balanced interrelation between the two main concepts given above will be given in conclusion.
\end{abstract}

Keywords: Tourism, Hospitality, cultural property, conservation

\section{Prologue}

As a conservation architect, and I will not discuss concepts related to tourism hospitality, tourism planning, types of tourism and the like in this paper. With a 42 year long experience of the conservation of cultural properties and natural values behind me, I will make an exposé of that experience (or a series of experiences) and comment on the interrelations and contradictions between tourism and architectural conservation. I will only give basic definitions of some concepts so that I can make my comments from the viewpoint of architectural conservation.

As a beginning, Tourism has a connotation of leisure travel and tends to be synonymous with holidays (vacations). In dictionaries as well, tourism refers to travel for pleasure.From the viewpoint of hospitality, tourism is generally related to the products to sell and the markets to serve. (Medlik, 2003, p.vii). I learned that 'hospitality' is used in different meanings. Dictionary definition is 'the act orpractice of being hospitable; the reception and entertainment of guests or strangers with liberality and goodwill' (The Shorter Oxford English Dictionary).Recently, the term refers to 'commercial' or 'professional' hospitality: the provision of accommodation, food and drink for people away from home for reward". (Medlik, 2003, p. vii). The word 'hospitality' can be defined as the provision of food,beverages and accommodation.I am well aware of the importance of the satisfaction of tourists, that is the customers of the tourism industry. Actually, this importance is the factor that sets the aim and scope of the type of tourism and hospitality industry in any country. It is a known fact that usage rate, or, "vacancy rate" is the primary variable of hospitality industry. Minimization of this rate is the fundamental factor behind the competition between the countries of interest for which the benefits gained through tourism is of vital importance. My limited observation shows that tourism income becomes even more important for countries during periods of financial crisis. In such instances

\footnotetext{
${ }^{1}$ Kemerburgaz University, Istanbul, Turkey.
} 
customers' satisfaction get extra priority and hospitality industry takes extra measures to minimize the vacancies.
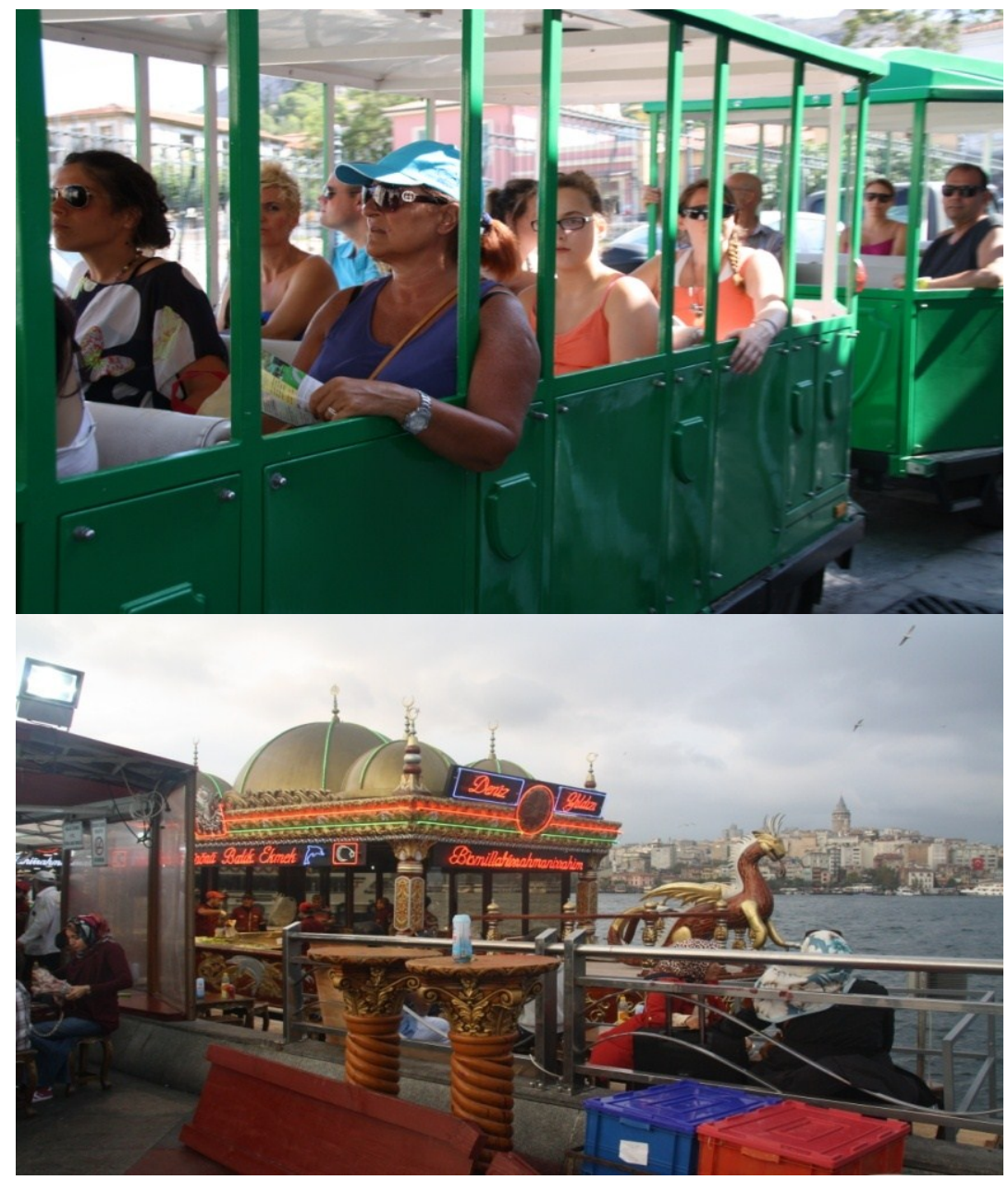

Fig. 1. Sight-seeing activities: a) Athens, b) İstanbul

Not only the qualities (or the luxury) of hotels, restaurants, entertainment facilities but also the loci of touristic activity becomes crucially important. This is where the problem, my problem, begins. 


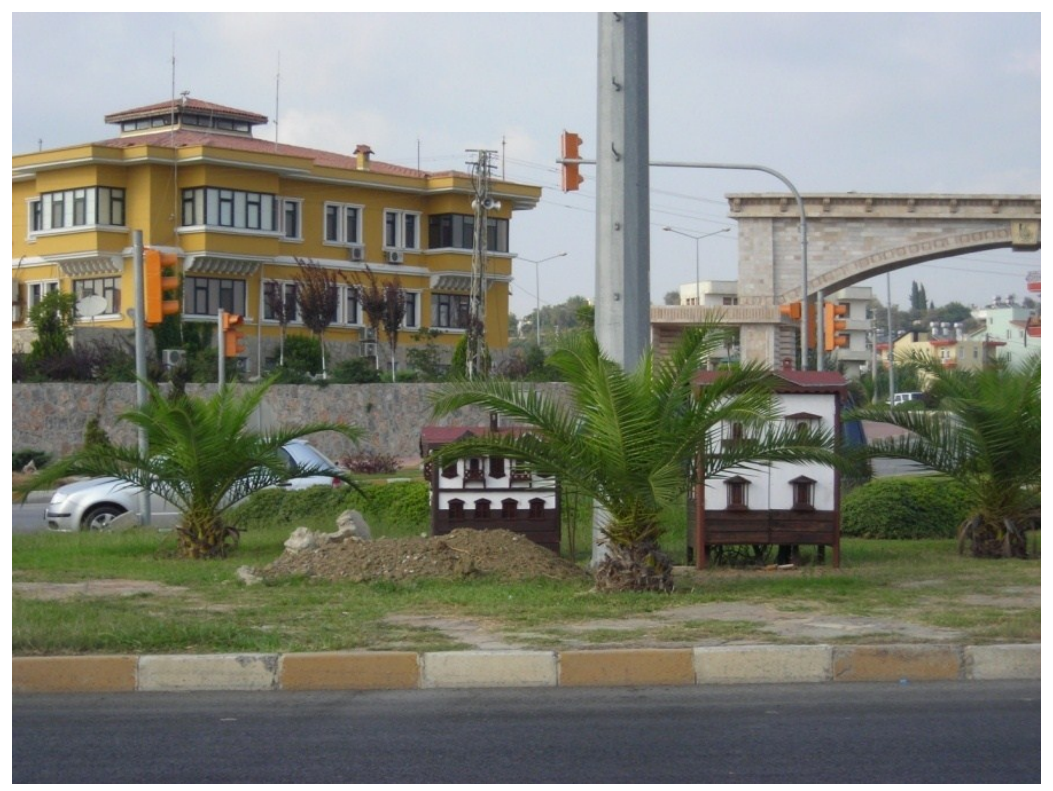

Fig. 2. New architecture emerged to attract tourists (Side) note the electricity cainets

It is obvious that seeing and experiencing new places is the fundamental factor in choosing a "place to go" for any tourist. Discovering new, exotic places, being part of a new environment that may be exciting or relaxing or even adventurous are primary attractions for tourists. Going to safari tours, staying at spartan conditions are such pseudo adventures that are to be lived, documented by photographs or videos and shared as life experiences. Less adventurous but more "culturally satisfying" for many people is visiting historic and traditional places. Today, tourism is far beyond the 3S concept of "sea-sun-sand" formula and especially upper cultural/socioeconomic group prefers to learn the cultural background of countries that they visit.Hard or soft, tourism used natural and historical values throughout centuries. Even archeology as a science began with the curiosities of travelers, especially from 18th century onwards. Going to Italy or Greece was very fashionable. People who wanted not only to see but also to learn from what they saw opened the gates of a new science, archaeology. And a natural follow-up for it were the concepts of restoration and conservation.

Once the priority becomes cultural tourism, implementations of restoration and conservation start accelerate. Tourists start to expect more and more "luxurious" cultural experiences that match the luxury of the establishments they live in. And this is the point where contradictory requirements emerge. 


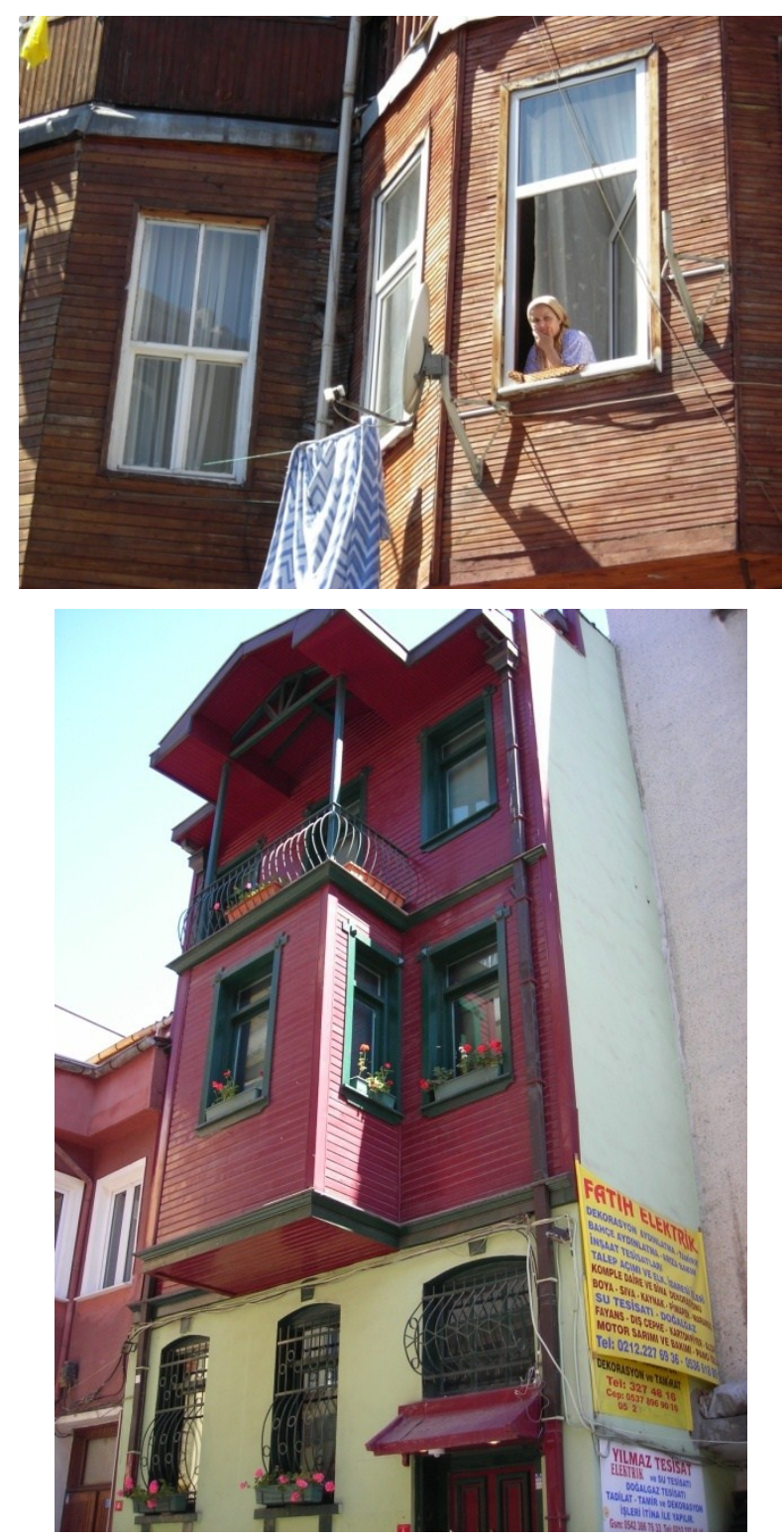

Fig. 3. A repaired house of native inhabitant (a) and (b) a "restored" house on the very same street, İstanbul

At this point it seems that the implementations of restoration and conservation have no limits. Yet, the fact is that the limit is set by qualities, characteristics, problems and the potentials of the cultural/natural values. 1964 Venice Charter formulates the dilemma: "Restoration stops where conjecture begins". Scientific circles accept and apply this to its widened context even today. Now, not only single buildings but also natural environmental characteristics as well as inhabitants living in these environments are important. All these aspects are not to be elaborate and sophisticated. Modest products of a culture, mobile or not, are valuable for humanity as long as they provide information about the community which created them. 
"Cultural Turism" comes into international platforms at this stage: One of the most important documents in the field is The Charter of Cultural Tourism prepared by ICOMOS in 1976. This paper discusses the positive and negative sides of tourism. Contribution of different specialists is taken as a positive point ( Article 3) whereas "...massive and uncontrolled use of monuments." (Article 4) by visitors is taken as the negative side. In the section of Basis of Action, the document "... expresses the wish that from school age onwards children and adolescents be educated to understand and respect to monuments,sites...". This criterion should still be an aim that Turkey tries to reach at.

In 1997, Charter on the Use of Ancient Places for Performance was declared by the Council of Europe. This document allows some special performances by taking necessary precautionsreducing the risk of damage to ancient sites.

12th General Assembly of ICOMOS, held in Verona in 1999 declared "International Cultural Tourism Charter". This may show that the problems could not be solved and get even more complicated in 10 years. This Charter stated that "... the natural and cultural values belong to all people. We each have a right and responsibility to understand, appreciate and conserve its universal values" (The Charter Ethos). Due to the increasing globalization in recent times, "... the conservation, interpretation and presentation of heritage and cultural diversity of any particular place or region is..." accepted as an important factor which requires constitution of a correct management plans for such areas. This scope is related to the dynamic and critical interrelation of heritage places and tourism (Principle 1). Principle 3 requires the necessity of assuring the visitors experiences to be worthwhile, satisfying and enjoyable while conserving and planning of heritage for touristic purposes. Involvement of host communities in this planning process is adviced in Principle 4. Conservation theories also bring very similar statements (Jokhilehto,1993).

For years, conservation circles tried to tell other sectors that scientific conservation is not a hindrance for the development of these sectors. On the contrary, creating a balanced development is one of the aims of conservation.

But, while securing that balance, it should not be overlooked that conservation requires honesty. Conservationist's aim is to convey information to coming generations without any deformation of the original messages. This is done through the material witnesses of the past, that is, the cultural properties. These express the signs and symbols in material form. That is why we cannot separate tangible values, values that we can touch, smell and taste, from intangible values which we can only detect through the properties that are conserved.

This is the process that has to be evaluated from the viewpoint of tourism hospitality and the limits of the consumer's, that is the tourist's, satisfaction and pleasure.

The concept has changed quite a lot in time.

The Icomos "Charter for the Interpretation and Presentation of Cultural Heritage Sites" states the below-mentioned decisions in 2008:

"Tangible and intangible values of cultural heritage sites must be safeguarded in their natural and cultural settings and social contexts. Respect The authenticity of cultural heritage sites, and the significance of historic fabric and cultural values must be protected from the adverse impact of infrastructure, visitor pressure, inaccurate or inappropriate interpretation. 
"Conservation of cultural heritage sites must ensure their long-term maintenance and promote public understanding and participation. Involvement of stakeholders and associated communities is very important."

The Paris Declaration On heritageas a Driver of Development,adopted at UNESCO Paris in 2011, aims "to measure the effects of globalisation on communities and heritage. It will then identify the actions needed not only to protect heritage, but also to ensure that its use, its promotion and enhancement, and its economic, social and cultural value are harnessed to the benefit of local communities and visitors. "The Florence Declaration on Heritage and Landscape as Human Values (2014) states that "All individuals and communities have the right to benefit from cultural heritage and landscape to the same extent that they have a duty to preserve its authenticity and cultural diversity as a human right". Protecting the spirit of "place" and people's identity must aim the improvement of their quality of life.

I have schematized the scientific theoretical approach above. The real-life situations come out very different.

Real-life realities put the attraction of the tourist at the top of the scale. And this instantly transforms the cultural property to "a tool, an object, a theater stage" of an un-real world. All architectural characteristics are changed, altered and even destroyed. Natural elements are modified, elaborated through non-native flora. Colors become more cheerful, LEDlighting schemes create theatrical, orientalist outlooks.

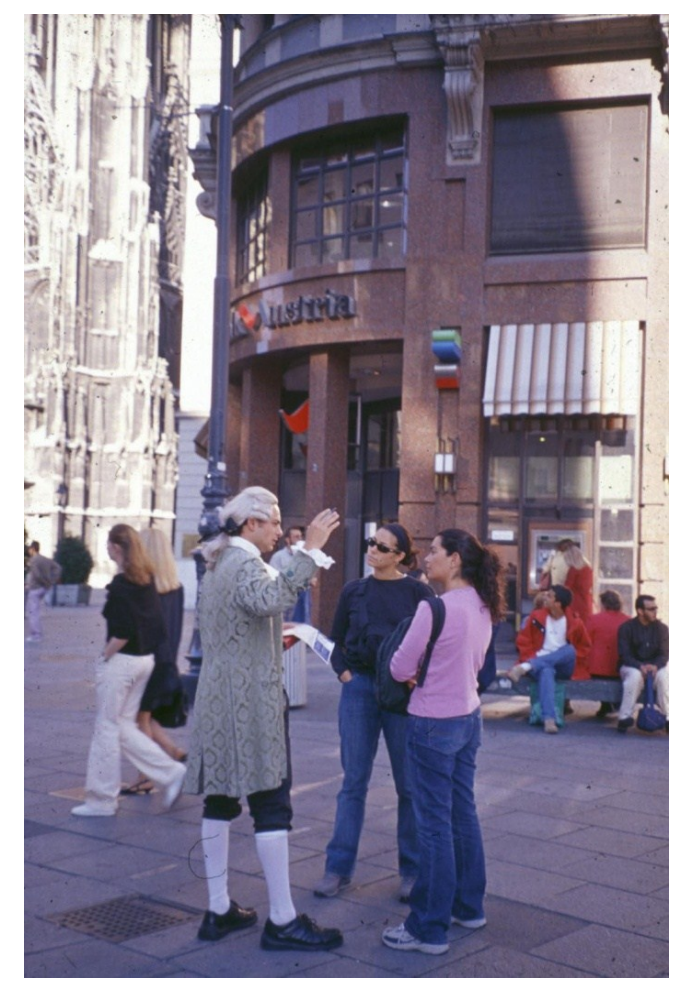

Fig 4. Touristic role playing, Vienna 
Many of the architectural characteristics are destroyed and reconstructed according to the needs (!) of touristic functions. Facades gain a pseudo-priority, but they become mostly imitated elements, ending up as beautiful but hybrid surfaces which have never-ever existed throughout history. - - - I will show a few examples to make my point.
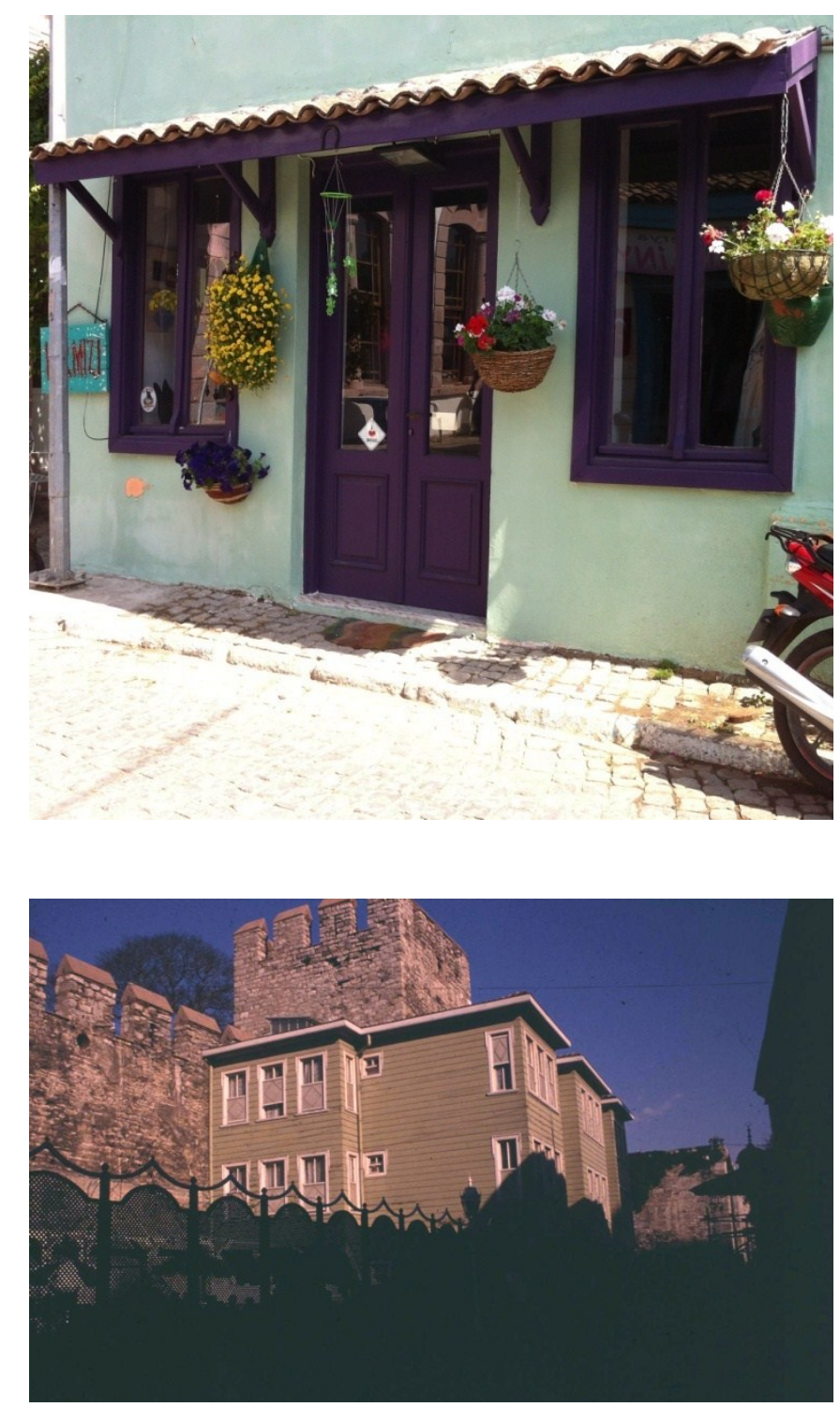

Fig 5. a) Color change in Ayvalık; b) Reconstruction in İstanbul: Both aiming beautification

It is inevitable to accept the cultural values of a country as an important factor attracting tourism. European countries also follow the same tendencies especially in these days. There are lots of cleaned white facades and touristic restorations. But in the case of Turkey, especially in the conservation of archaeological sites, the aim and the tools has changed their roles. 
Conservation aims at the continuation of the cultural properties to the younger generations in a sound state by giving correct information. Tourism, by definition is a tool for this aim and should be very carefully defined. Gaining more income through tourism is a policy of Turkey similar to other countries. But $5^{*}$ hotels and $3 \mathrm{~S}$ understanding which had failed decades ago in the case of Spain. The result of this policy affected the profile of tourists coming: Only $9 \%$ of them are now coming to Turkey for cultural purposes. So, the quality of visitors are lower and many of the cultural values are spent for the sake of this result.

The destruction caused by the use of antique theater for several concerts cannot be compansated by the income of ticket sales. This experience was lived in Italy in 1970s and failed. The results are obvious: Vibration, air pollution, extra load of the motor traffic ... Introduction of thousands of people to the site without control, effects of electronic equipments for high-volume performances are known. So, this choice is not correct way of representing our cultural past to the visitors.

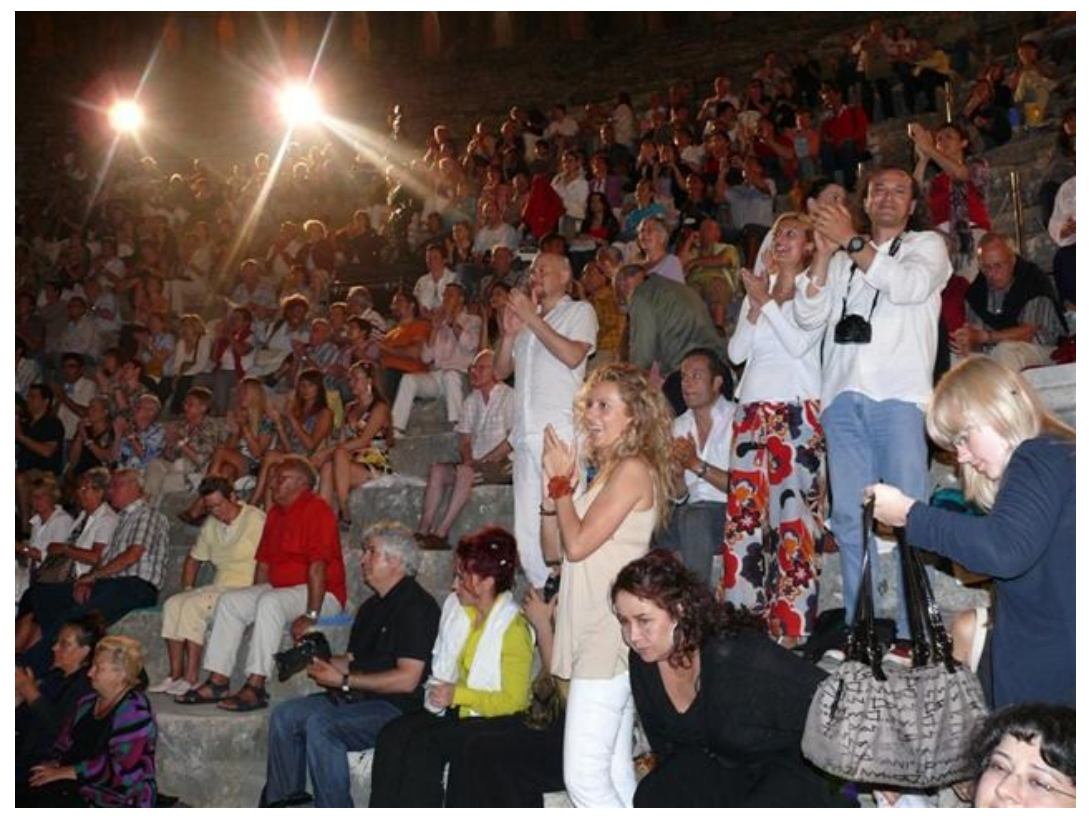

Fig. 6. Aspendos: Thousands of visitors in an antique theater

Only $2-3 \%$ of the national budget is being used for the sector of culture in Turkey. Compensation of the shortage of budget should not mean privatization of conservation activities. This is not totally rejected if necessary measures to control the implementations are set. But, the risk of further damage cannot be underestimated. This will mean squandering our cultural identity which will cause a break in the continuity of culture of a nation.

That is why these cultural properties are not called as "heritage". They are the values to be preserved for the coming generations and not for spending them in advance. (Asatekin 1998) 

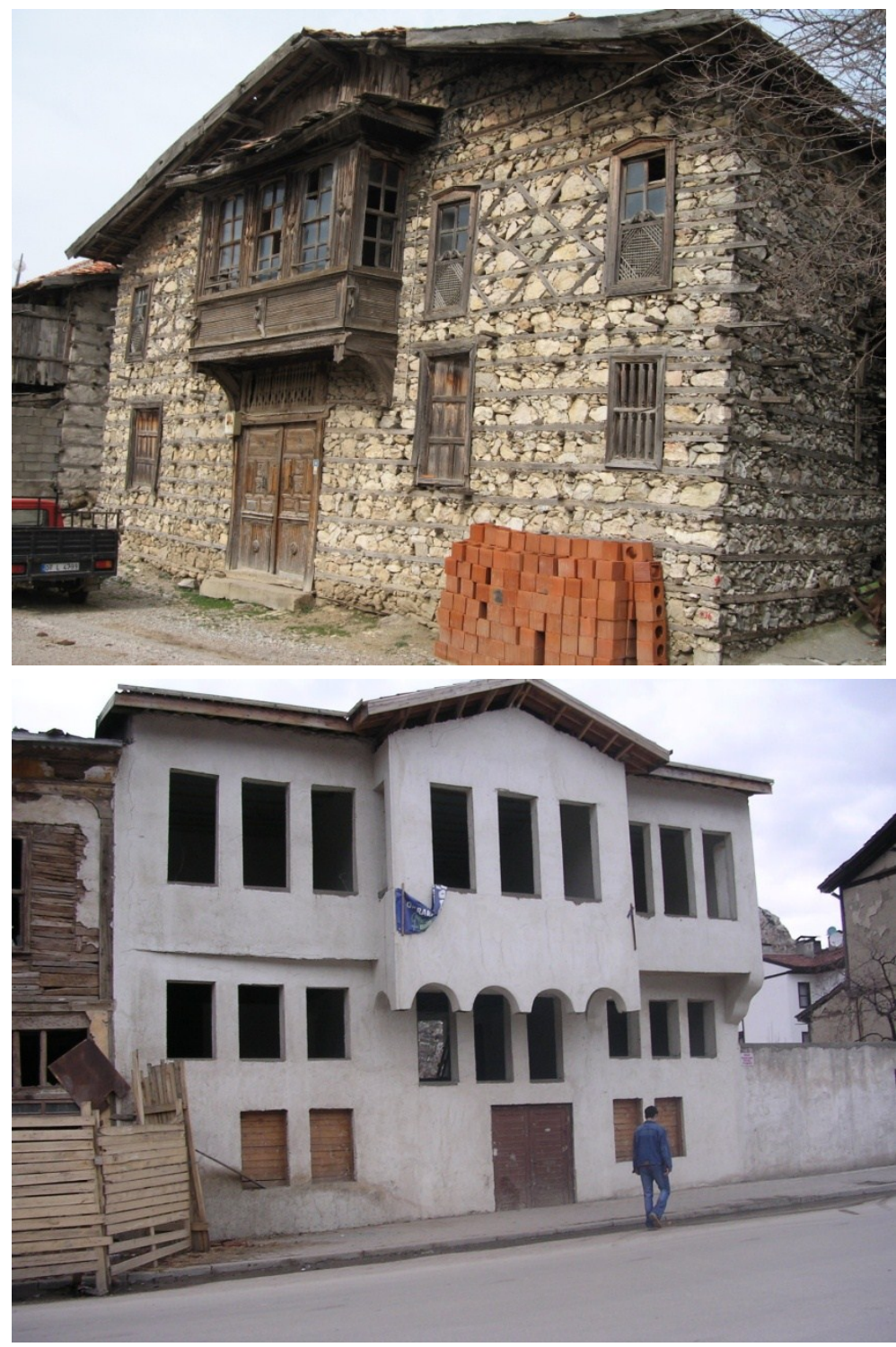

Fig. 7. a) Original traditional dwelling in Ormana, b) Interpretation of the very same architecture in Milas 

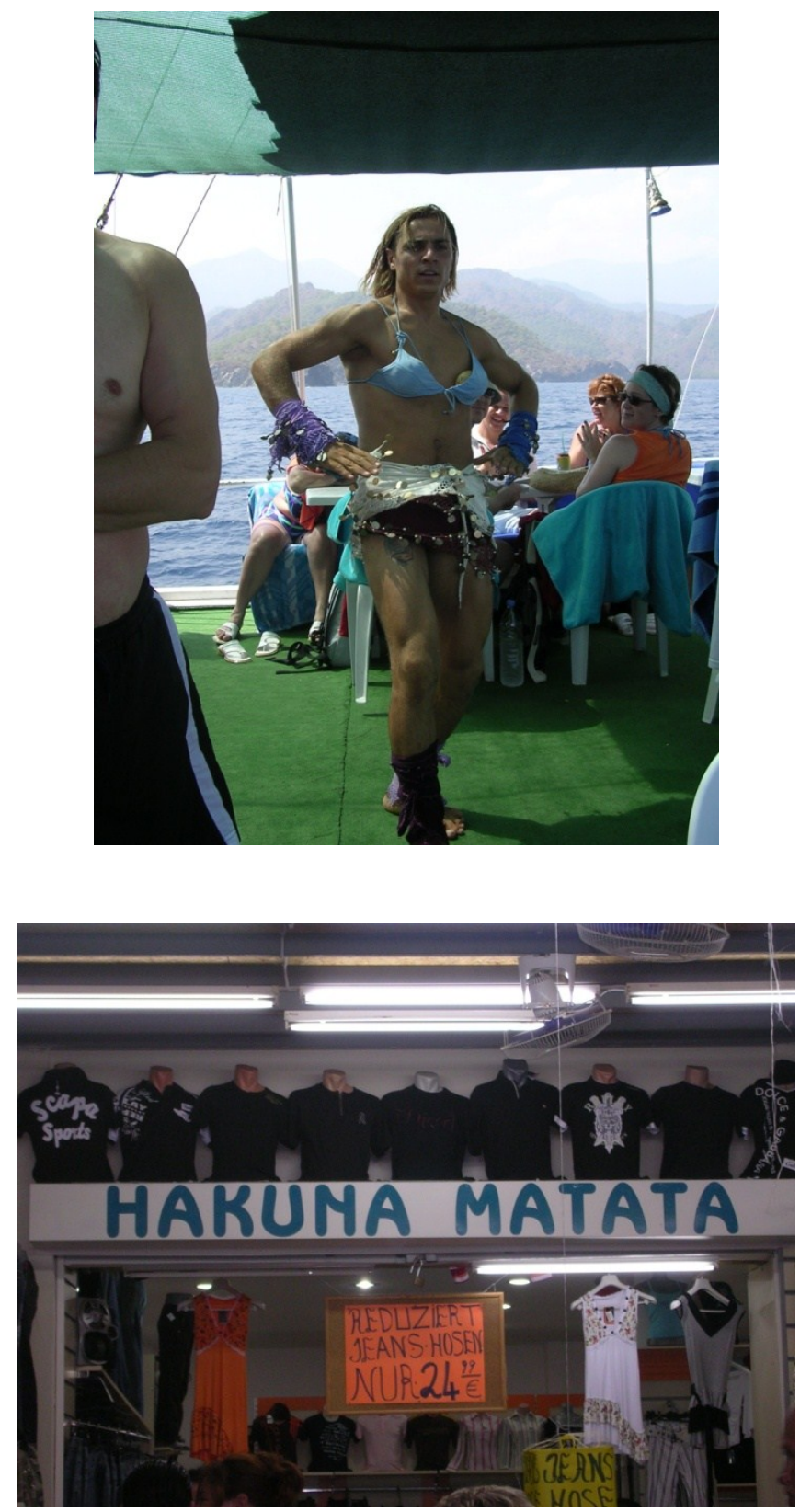

Fig 8. a) and b) Tourism hospitality: Social and architectural impact

Besides the damage given to the physical environment, we should not overlook the social side of the impact. Once changes start to take place, native inhabitants become forced to leave their homes. There are several reasons behind this gentrification. Land prices and rents increase rapidly, many of the original owners are not wealthy enough to restore their buildings, residential neighborhood transforms to a touristic district and life patterns start to change. Domestic functions decline, recreation activities that continue throughout night time disturb people, interaction between neighbors erodes and disappears. Traditional values disappear one by one. 
This is a total socio-economic change. ... Yet, this is not final.

Because of the declining historical - traditional values of a settlement, profile of the visitors start to change. Cultural tourism gives way to a mass tourism which is dominated by lower cultural groups. Kitsch products begin to spread, taste of the users as well as the serving group decline. This is a vicious circle and neither tourism nor cultural properties can benefit from this uncontrolled change.

This process always makes me ask this question: "For whom we try to conserve historic traditional environments?" The aims of scientific conservation totally fail in many cases. Neither architectural conservation is a tool for conservation proper, nor tourism is the only tool of realization of conservation.

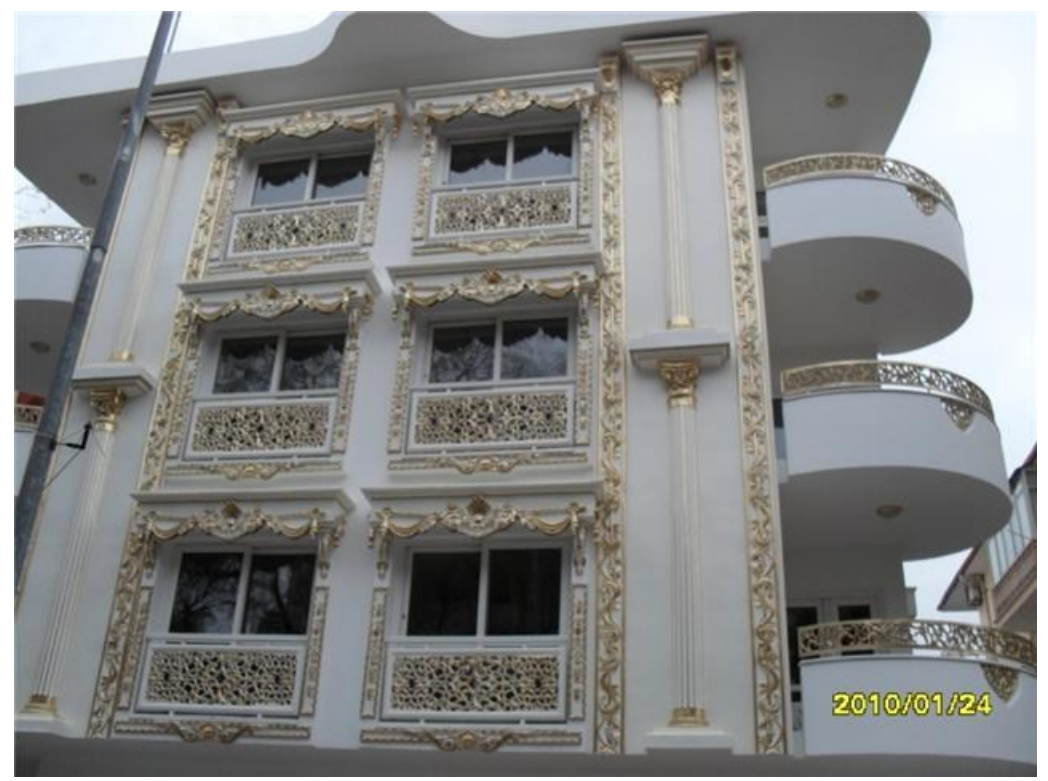

Fig. 9. Tradition is lost....

I know that there is not a general rule that can be accepted internationally. It is always a caso per caso situation. And it leads to a scope that each influencing factor should be analyzed and evaluated in detail.

Our aim should be to convey the cultural properties honestly and as valuable assets of every community's identity. To this end, I feel that I need to note that expected satisfaction of the visitors from the tourism-hospitality industry should be based upon:

- Experiencing the native and original characteristics of the environment that they visit,

- New functions for the cultural properties must be given according to their historicalarchitectural spatial organizations-qualities. Only in this way people can learn the cultural values expressed by the physical environment they are experiencing. Fake spaces and buildings means lying to people and giving wrong messages pertaining to their value. This is totally against the aims of both conservation and specializations of tourism hospitality. 


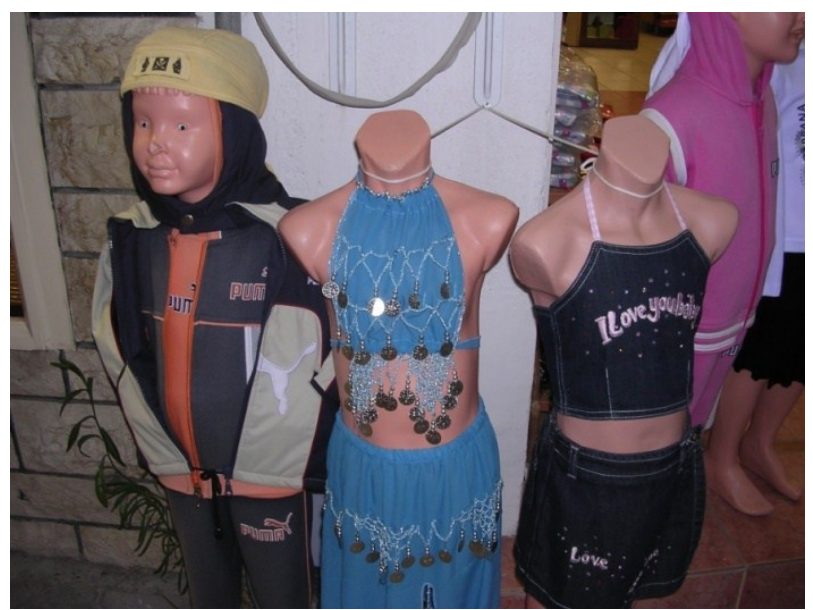

Fig 11. Kitsch spreads....

- The local inhabitants are to be part of the whole project so that they continue to live in the environment they belong to. This will give the correct message about the sociocultural and tangible characteristics of the visited site. Yet, there is a very delicate balance which all contributing parties must take into consideration: Local inhabitants are not actors performing on a theater stage to satisfy tourists. They are to be a part of the planning activity as real owners of the area.

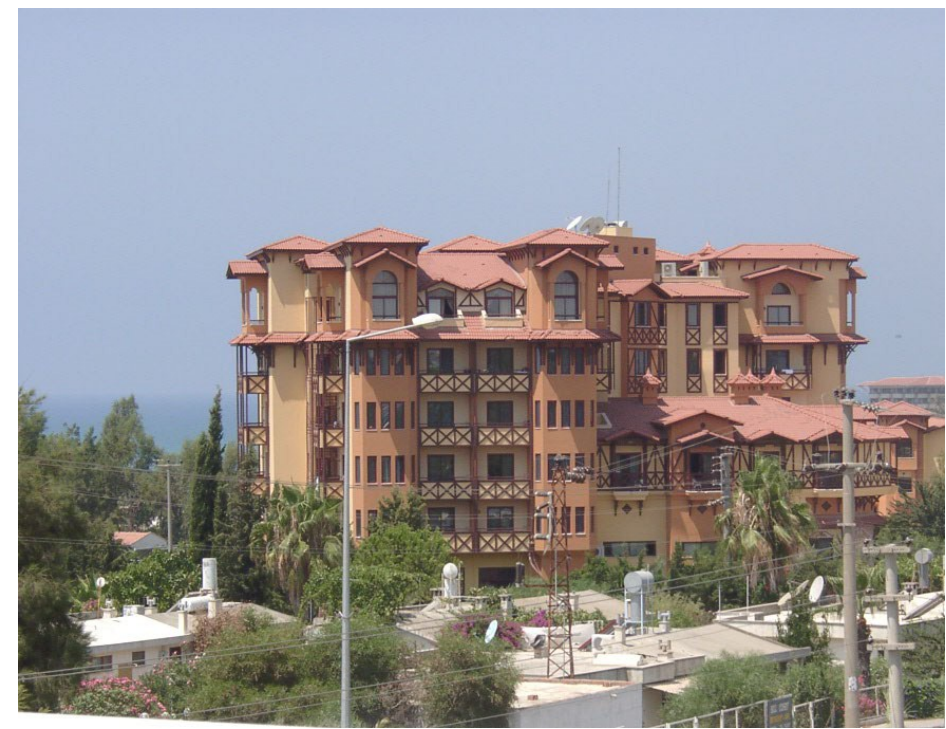

Fig. 12.Kitsch architecture trying to copy "traditional”, Side

- New buildings to fulfill the needs and requirements of the touristic spatial organization should not be pseudo-historic buildings, presenting themselves as beautified hybrid restorations. They should be designed as contemporary interpretations in harmony with the historic environment and buildings.

- Nature and flora should be respected. Using alien trees and flowers may look exotic and interesting to tourists but they completely ruin the character of the site. 
All in all, if the aim is the maximization of the user satisfaction in hospitality industry, we should not overlook the fact that user satisfaction is possible only by conveying the correct information from the past and making clear the characteristics of the specific cultures the target group is experiencing.

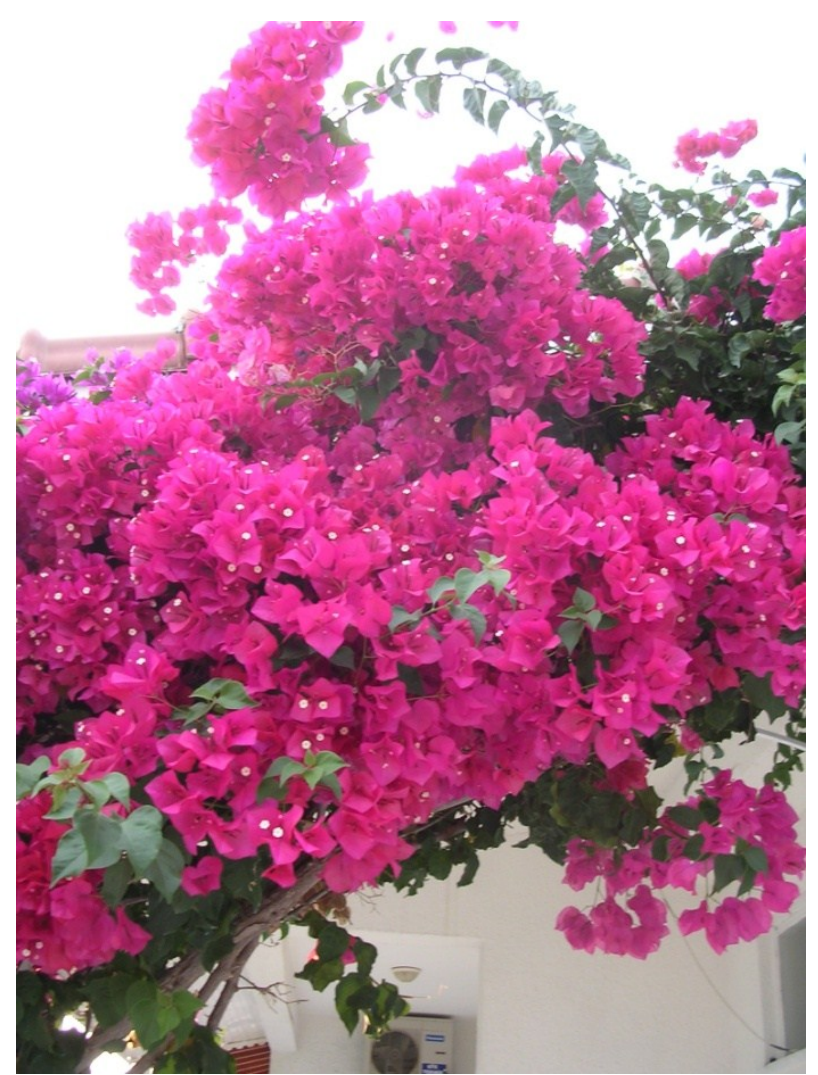

Fig. 13. Native flora of Mediterrenean: Baugainvilla.

\section{Epilogue}

All countries must find the answer Ricoeur's famous paradox "becoming modern and to return to sources.." (Ricoeur,1993:271). As long as universal civilization requires scientific sprit in the spread of techniques, native solutions (Ricoeur,1993: 279-281) without eliminating the rooted culture flourished in this country should be found.

\section{REFERENCES}

1. ASATEKİN, N. Gül (2007) “Antalya Kent Kimliği: Estetik Kurul Gerekli mi?”, Batı Akdeniz Mimarlık, No.6,s.70-75.

2. ASATEKIN, N. Gül (2005) "Understanding Traditional Residential Architecture in Anatolia", Journal Of Architecture, C. 10, No. 4, s.389- 414. 
3. ASATEKİN, N. Gül (2005) Neyi, Niçin, Nasıl Korumalıyız? (Editör: Koray Olşen, Yayınlar Şubesi Müdürü, Kültürve Turizm Bakanlığı),.Kültürve Turizm Bakanlığı Yayını, Milli Kütüphane Basımevi, Ankara.

4. RICOEUR, P. (1965 ). "Universal Civilization and National Culture", History and Truth, Northwestern University Press, Illinois.

5. Feilden B.M., Jokhilhto, J. ( 1993). Management Guidelines for Cultural Heritage, ICCROM.

6. Recommendation of International Principles Applicable to Archaeological Excavations ( 1956 ).New Delhi,5 December 1956.

7. The ICOMOS Charter on Cultural Tourism, Brussels, 1976.

8. International Charter for Archaeological Heritage Management, 1990, ICOMOS.

9. Document of Nara, 5 November 1995, ICOMOS, ICCROM.

10. International Cultural Tourism Charter, Mexico, 1999.

11. “Tarih Özelleşiyor”, Tourism Today, No.15, s.22-23, 2004.

12. "Concept of Tourism and Hospitality", http://www.adameurope.eu/prj/10485/prj/Definition\%20of\%20Tourism.pdf)

13. http://www.arkitera.com/haberler/2002/09/14/efes.htm

14. http://www.neetepc.com/shop.asp

15. http://www.focusdergisi.com.tr/arkeoloji/00367/+efes +

16. http://www.efespilsen.com.tr/e arkeoloji2.asp

17. http://www.unesco.org

18. http://www.1comos.org 